\title{
Ragam Cara Portal Berita Indonesia Tarik Partisipasi User
}

\author{
Gilang Desti Parahita
}

Dewan Pers mencatat setidaknya terdapat 43.000 situs berita berbasis di Indonesia namun hanya 2.700 portal berita yang terverifikasi Dewan Pers (AMSI, 2019). Proliferasi pers online itu didorong oleh kebebasan pers yang mekar pada Reformasi (Hill \& Sen, 2000) dan makin dilesatkan oleh penetrasi telepon genggam di Indonesia (Manan, 2013). Sebagian situs berita online itu merupakan bagian dari konglomerasi media di Indonesia (Dewan Pers \& PR2Media, 2015). Perusahaan-perusahaan itu adalah MNC Group, Kompas Gramedia Group, Elang Mahkota Teknologi, Visi Media Asia, Grup Jawa Pos, Mahaka Media, CT Group, BeritaSatu Media Holdings, Grup Media, MRA Media, Femina Group and Tempo Inti Media (Nugroho, et.al., 2012). Sebagian perusahaan media baru lainnya, sedangkan sisanya adalah perusahaan media yang digolongkan sebagai usaha media rintisan (startup media). Teknologi konvergensi dan konglomerasi itu turut membentuk nilai profesional dan peran jurnalisme Indonesia kontemporer 
(Sumartias \& Hafizni, 2017; Souisa, 2017; Dharmasaputra, 2011; Hanitzsch, 2005).

Di tengah perubahan itu, interaktivitas antara pengguna (user) dan jurnalis online Indonesia masih belum dipetakan bentuk dan kedalamannya. Sebelum 2010, sejumlah riset mengindikasikan hubungan jurnalis-penulis masih berkutat pada tradisi "Saya menulis, Anda membaca" (Luik, 2009; Massey \& Levy, 1999). Namun menurut pengamatan penulis, sejumlah portal berita di Indonesia mulai meninggalkan tradisi tersebut. Portal-portal tersebut tidak hanya menggunakan cara konvensional untuk menarik partisipasi audiens, namun juga cara-cara yang lebih inovatif di mana unsur kolaborasi menguat.

Sebelum era media baru, partisipasi user pada alur produksi berita masih terbatas. Hubungan audiens-jurnalis cenderung diabaikan oleh pengelola media (MacGregor, 2007). Akan tetapi secara paradoks pengelola media memahami audiens secara terbatas melalui kerja-kerja divisi pemasaran (McChesney \& Robert W., 2003; McManus, 1994; Meehan, 1995). Pada era sebelum Internet tersebut, jurnalis cenderung untuk meyakini diri mereka sendiri dalam memaknai nilai berita dan profesionalisme. Mereka seakanakan telah mengerti dengan serta merta apa yang audiens inginkan meski tidak memiliki hubungan langsung dengan audiens (Schlesinger, 1987; Gans, 1980). Audiens tidak diperhitungkan dalam benak jurnalis karena para jurnalis umumnya menghabiskan waktu dengan sumber-sumber (Tunstall, 1971). Selain itu, jurnalis dan editor cenderung untuk membahas masalah-masalah dalam komunitas jurnalistik tanpa menghadirkan audiens (Sumpter, 2000). Alasannya adalah jurnalis berusaha untuk selalu "independen dan otonom" (Splichal \& Sparks, 1994).

Pada era Internet, organisasi media dan jurnalis semakin menilai penting partisipasi audiens pada alur produksi berita. Fitur interaktivitas pada media online memungkinkan terjadinya interaksi 
baik antar pengguna, pengguna dan algoritma, maupun pengguna dengan jurnalis/ moderator (Deuze, 2003). Untuk memaksimalkan potensi partisipasi melalui fitur interaktivitas pada situs web berita, portal berita dapat menempuh tiga cara. Ketiga cara tersebut tersebut ditemukan pada lansekap industri media di Indonesia.

Cara konvensional untuk mengumpulkan atensi dari user adalah pertama, media konglomerasi mempertahankan kendali atas konten dan atensi audiens termasuk atensi pengguna pada jejaring perusahaan media tersebut (Cohen, 2002; Nixon, 2020). Hal itulah yang terjadi pada konglomerasi media di Indonesia. Konglomerasi media di Indonesia menguat saat CT Grup mengakuisisi Detik.com, Lippo Group bergabung dengan Beritasatu.com dan Emtek Group yang memiliki SCTV dan O-Channel mengakuisisi Indosiar pada 2011 (Nugroho, Putri, \& Laksmi, 2012). Ketiga akuisisi itu semakin menguatkan atensi user pada konten yang dikreasi oleh jejaring media konglomerat itu. Pada saat yang sama, konglomerasi mengurangi independensi media berita sebab para pemilik media terlibat dalam kegiatan politik dan aktivitas bisnis di luar media yang berpotensi menumpulkan kritisisme masing-masing media. Pada 2016-2017, kompleks pemukiman dan pertokoan Meikarta di Cikarang yang dikembangkan oleh Lippo Group disinyalir tidak memiliki perizinan analisis dampak lingkungan (Amdal) maupun izin mendirikan banguan (IMB). Analisis isi menunjukkan pemeritaan Beritasatu.com memberikan ruang bagi pihak Lippo Group untuk membantah tuduhan-tuduhan itu daripada pemberitaan Kompas.com (Yusman, 2018) meski Beritasatu.com menyediakan panduan Jurnalisme Positif: Panduan Kerja Para Jurnalis Berita Satu Holding yang mencantumkan keberimbangan dalam pemberitaan (Manajemen BeritaSatu Media Holdings, 2012). Saat ini Detik.com juga berjejaring dengan portal berita franchise asing yaitu CNNIndonesia.com dan CNBCIndonesia.com. Dengan menyerbu audiens dari berbagai kanal, media konglomerasi menarik partisipasi user melalui aktivitas menyimak siaran maupun 
membaca konten online yang menaikkan rating siaran dan trafik kunjungan online.

Cara konvensional lainnya adalah media membangun hubungan yang dialogis dengan user (Lewis, 2012). Kolom komentar; kuis dan poling instan; penyusunan hirarki konten seperti yang paling banyak dibaca/ didiskusikan/ dibagikan, dan tombol berbagi serta rekomendasikan merupakan sejumlah partisipasi yang mungkin terjadi pada suatu situs berita (Manosevitch \& Tenenboim, 2017; Barnes, 2014). Melalui interaksi audiens terhadap maupun dalam situs web itu, media berita dapat menggunakan dan menganalisis data metrik perilaku user (MacGregor, 2007). User mampu berpartisipasi sebagai sumber-sumber dan menyediakan informasi kepada jurnalis profesional. Selain itu, user bisa terlibat dalam percakapan satu sama lain maupun dengan pekerja berita, dan mendorong transparansi proses produksi berita (Kammer, 2013).

Cara konvensional di mana portal berita menyediakan kolom komentar pada tiap artikelnya telah menjadi semacam norma yang dipraktikkan pada portal berita global, termasuk Indonesia. Namun cara itu semakin tidak mendapatkan perhatian dari user. Media sosial seperti Facebook dan Instagram telah menjadi ruang sosial virtual bagi para user. Partisipasi user melalui komentar tidak lagi dilakukan langsung pada portal berita, melainkan pada akun-akun organisasi berita di media sosial. Kunjungan ke situs web menurun sebab kunjungan hanya sebatas untuk membaca berita dan tidak untuk memberikan komentar maupun menimpali komentar warganet yang lain. Implikasinya, portal berita dan jurnalis online berupaya meningkatkan klik dari judul-judul berita yang ditautkan di akun-akun media sosial mereka. Tidak heran, judul-judul yang clickbait (memancing klik) dan bernada sensaional menjadi pola baru pada banyak portal berita di Indonesia (Suciati \& Fauziah, 2020). 
Nixon (2017) mengingatkan bahwa pada era ekonomi perhatian, bukan berarti perusahaan media terbawa arus menyajikan berita yang semata-mata sedang menjadi tren. Menurut Nixon (2017:17) perusahaan media dapat menarik perhatian audiens manakala user mendapatkan konten yang berkualitas dan berharga. Nixon (2017:14) tidak setuju dengan gagasan bahwa Teori Ekonomi Perhatian (attention economy theory) mengasumsikan perhatian sebagai sumber daya. Menurutnya, perhatian adalah aktivitasaktivitas yang dikreasi agar dapat dikendalikan dan menjadi sumber nilai industri suratkabar. Apabila perhatian diperlakukan sebagai sebuah aktivitas, pelaku industri pers dapat mengendalikan aktivitas itu. Aktivitas-aktivitas itu perlu dikondisikan agar itu menjadi sumber nilai bagi industri suratkabar misalnya dengan menghasilkan berita yang berkualitas terlebih dahulu. Digital paywall menurut Nixon (2017) dapat dijadikan cara mendapatkan dolar dari perhatian tersebut. Tembok berbayar merupakan bentuk kuasa atas konsumsi audiens yang memungkinkan perusahaan berita mengeksploitasi kerja audiens. Upaya menyajikan berita yang "unik dan berbeda" untuk menarik audiens itulah yang tampaknya sedang dilakukan oleh sejumlah situs seperti yang terangkum pada Tabel 1. Keunikan itu terletak pada konsep pengelolaan portal, fokus pemberitaan dan pendekatan jurnalisme yang dipraktikkan.

Tabel 1. Data Sejumlah Portal Berita di Indonesia

\begin{tabular}{|c|c|c|c|c|c|c|}
\hline $\begin{array}{l}\text { N } \\
\text { o. }\end{array}$ & $\begin{array}{l}\text { Nama } \\
\text { media }\end{array}$ & $\begin{array}{l}\text { Tahun } \\
\text { berdiri }\end{array}$ & CEO & $\begin{array}{c}\text { Investor/ } \\
\text { Pemilik/Pen } \\
\text { diri }\end{array}$ & $\begin{array}{l}\text { Status } \\
\text { di } \\
\text { Dewan } \\
\text { Pers }\end{array}$ & Keunikan \\
\hline 1 & $\begin{array}{l}\text { Dailysoc } \\
\text { ial.id }\end{array}$ & 2008 & $\begin{array}{l}\text { Rama } \\
\text { Mamuay } \\
\text { a }\end{array}$ & $\begin{array}{l}\text { PT Digital } \\
\text { Startup } \\
\text { Nusantara, } \\
\text { PT Global } \\
\text { Digital Prima }\end{array}$ & $\begin{array}{l}\text { Tidak } \\
\text { ada }\end{array}$ & $\begin{array}{l}\text { Menyajikan } \\
\text { berita dan } \\
\text { informasi } \\
\text { tentang } \\
\text { perusahaan } \\
\text { rintisan } \\
\text { teknologi. }\end{array}$ \\
\hline
\end{tabular}




\begin{tabular}{|c|c|c|c|c|c|c|}
\hline 2 & $\begin{array}{l}\text { Goodne } \\
\text { wsfromi } \\
\text { ndonesi } \\
\text { a.id }\end{array}$ & 2009 & $\begin{array}{l}\text { Wahyu } \\
\text { Aji }\end{array}$ & $\begin{array}{l}\text { Akhyari } \\
\text { Hananto }\end{array}$ & $\begin{array}{l}\text { Tidak } \\
\text { ada }\end{array}$ & \begin{tabular}{lr}
\multicolumn{2}{l}{ Menyajikan } \\
berita dalam \\
nada & yang \\
positif & dan \\
optimis & \\
\end{tabular} \\
\hline 3 & $\begin{array}{l}\text { IDNTim } \\
\text { es.id }\end{array}$ & 2014 & $\begin{array}{l}\text { Winston } \\
\text { Utomo }\end{array}$ & $\begin{array}{l}\text { IDN Media/ } \\
\text { Winston } \\
\text { Utomo dan } \\
\text { William } \\
\text { Utomo }\end{array}$ & $\begin{array}{l}\text { Terveri } \\
\text { fikasi } \\
\text { Admini } \\
\text { strasi } \\
\text { dan } \\
\text { Faktua } \\
\text { I }\end{array}$ & $\begin{array}{l}\text { Menyasar } \\
\text { generasi } \\
\text { milenial dan } \\
\text { Gen-Z, } \\
\text { menggabungka } \\
\text { n UGC dan } \\
\text { konten redaksi. }\end{array}$ \\
\hline 4 & $\begin{array}{l}\text { Katadat } \\
\text { a.co.id }\end{array}$ & 2012 & $\begin{array}{l}\text { Metta } \\
\text { Dharma } \\
\text { saputra }\end{array}$ & $\begin{array}{l}\text { Tidak } \\
\text { diketahui }\end{array}$ & $\begin{array}{l}\text { Terveri } \\
\text { fikasi } \\
\text { Admini } \\
\text { strasi } \\
\text { dan } \\
\text { Faktua } \\
\text { I }\end{array}$ & $\begin{array}{l}\text { Menyajikan } \\
\text { berita, } \\
\text { informasi, data, } \\
\text { dan hasil riset } \\
\text { secara } \\
\text { mendalam } \\
\text { dalam bentuk } \\
\text { teks dan visual; } \\
\text { menyasar } \\
\text { kalangan bisnis } \\
\text { dan pengambil } \\
\text { kebijakan. }\end{array}$ \\
\hline 5 & $\begin{array}{l}\text { Kumpar } \\
\text { an.com }\end{array}$ & 2017 & $\begin{array}{l}\text { Hugo } \\
\text { Diba }\end{array}$ & $\begin{array}{l}\text { PT Dynamo } \\
\text { Media } \\
\text { Network, PT } \\
\text { Global } \\
\text { Digital } \\
\text { Prima, Go- } \\
\text { Jek, para } \\
\text { juralis eks- } \\
\text { Detik.com }\end{array}$ & $\begin{array}{l}\text { Terveri } \\
\text { fikasi } \\
\text { Admini } \\
\text { strasi } \\
\text { dan } \\
\text { Faktua } \\
\text { I }\end{array}$ & $\begin{array}{l}\text { Menggabungka } \\
\mathrm{n} \text { UGC dan } \\
\text { konten redaksi. }\end{array}$ \\
\hline 6 & $\begin{array}{l}\text { Lokadat } \\
\text { a.id }\end{array}$ & 2015 & $\begin{array}{l}\text { Herman } \\
\text { Kwok }\end{array}$ & $\begin{array}{l}\text { Najwa } \\
\text { Shihab, PT } \\
\text { Lintas Cipta } \\
\text { Media, anak } \\
\text { perusahaan } \\
\text { PT Global } \\
\text { Digital } \\
\text { Prima/ GDP } \\
\text { Venture }\end{array}$ & $\begin{array}{l}\text { Tidak } \\
\text { ada }\end{array}$ & \begin{tabular}{l}
\multicolumn{2}{l}{ Menyajikan } \\
laporan khas, \\
hasil riset dan \\
analisis baik \\
dalam bentuk \\
teks maupun \\
grafis \\
video.
\end{tabular} \\
\hline 7 & $\begin{array}{l}\text { Mongab } \\
\text { ay.co.id }\end{array}$ & 2012 & $\begin{array}{l}\text { Ridzki R. } \\
\text { Sigit }\end{array}$ & $\begin{array}{l}\text { Rhett A. } \\
\text { Butler/Mong } \\
\text { abay.com }\end{array}$ & $\begin{array}{l}\text { Tidak } \\
\text { ada }\end{array}$ & $\begin{array}{l}\text { Memiliki fokus } \\
\text { khusus pada } \\
\text { hutan, tetapi } \\
\text { juga } \\
\text { menyediakan }\end{array}$ \\
\hline
\end{tabular}




\begin{tabular}{|c|c|c|c|c|c|c|}
\hline & & & & & & $\begin{array}{l}\text { berita, analisis, } \\
\text { dan informasi } \\
\text { lain yang } \\
\text { berhubungan } \\
\text { dengan } \\
\text { lingkungan. }\end{array}$ \\
\hline 8 & $\begin{array}{l}\text { Narasi.t } \\
\mathrm{v}\end{array}$ & 2017 & $\begin{array}{l}\text { Zen } \\
\text { Rahmat } \\
\text { Sugito }\end{array}$ & $\begin{array}{l}\text { PT Narasi } \\
\text { Media } \\
\text { Pracaya, PT } \\
\text { Global } \\
\text { Digital } \\
\text { Prima/ GDP } \\
\text { Venture }\end{array}$ & $\begin{array}{l}\text { Terveri } \\
\text { fikasi } \\
\text { Admini } \\
\text { strasi } \\
\text { dan } \\
\text { Faktua } \\
\text { I }\end{array}$ & $\begin{array}{l}\text { Menyajikan } \\
\text { program } \\
\text { bincang- } \\
\text { bincang, } \\
\text { dokumenter, } \\
\text { opini dan } \\
\text { menyediakan } \\
\text { ruang interaksi, } \\
\text { mengelola } \\
\text { komunitas, dan } \\
\text { menyelenggara } \\
\text { kan event } \\
\text { offline maupun } \\
\text { online. }\end{array}$ \\
\hline 9 & Tirto.id & 2016 & $\begin{array}{l}\text { Sapto } \\
\text { Anggoro }\end{array}$ & $\begin{array}{l}\text { Mandiri oleh } \\
\text { Sapto } \\
\frac{\text { Anggoro (Pe }}{\text { mimpin }} \\
\text { Redaksi/ } \\
\text { Penanggung } \\
\text { Jawab), Teg } \\
\text { uh Budi } \\
\text { Santoso } \\
\text { (Chief } \\
\text { Content } \\
\text { Officer) dan } \\
\frac{\text { Nur }}{\text { Samsi (Chie }} \\
\text { f } \\
\text { Technology } \\
\text { Officer). }\end{array}$ & $\begin{array}{l}\text { Terveri } \\
\text { fikasi } \\
\text { Admini } \\
\text { strasi } \\
\text { dan } \\
\text { Faktua } \\
\text { I }\end{array}$ & $\begin{array}{l}\text { Menerapkan } \\
\text { jurnalisme } \\
\text { presisi, analisis } \\
\text { data statistik } \\
\text { maupun data } \\
\text { raksasa, juga } \\
\text { menyajikan } \\
\text { berita secara } \\
\text { mendalam } \\
\text { (Ciptadi } \\
\text { Armando, } \\
\text { 2018) }\end{array}$ \\
\hline
\end{tabular}

Sumber: www.dewanpers.or.id/data/perusahaanpers, Erlangga (2015),

Setyowati (2018) dan Upperline (2017), Santi Dewi (2018).

Terakhir, banyak media berita menghasilkan beragam bentuk berita melalui partisipasi audiens yang lebih kolaboratif misalnya dengan menghadirkan jurnalisme warga pada sejumlah perusahaanperusahaan media (Wahl-Jorgensen et al., 2016; Hujanen, 2016; Kammer, 2013; Bergström, 2008). User atau jurnalis warga dapat 
mengeksebisikan foto, video, cerita pengguna, dan bahkan menarik iuran bersama (crowd sourcing). Lebih dari sekedar angka statistik, user dapat dipahami sebagai produser (producer and user) (Bruns, 2009). Sebagai produser, partisipasi user menghasilkan user/consumer generated content (UGC/CGC). Banyak media global untuk menyediakan platform user generated content bagi audiensnya sejak awal kemunculan (Hermida \& Thurman, 2007; Thurman, 2008).

Pada kategori kolaboratif itu, Kompasiana.com yang dikelola oleh Kompas.com telah menjadi wadah bagi user untuk berkontribusi sebagai jurnalis warga. Kompasiana.com pernah dikritik karena konten user digunakan sebagai berita oleh jurnalis Kompas.com (Lase, 2014). Saat ini, Kompasiana.com telah menjadi portal yang menyediakan reward berupa rupiah bagi para penulisnya. Tampaknya hal itu mengindikasikan Kompasiana.com cukup mampu menghasilkan rupiah dari trafik yang terbentuk oleh komunitas produser/jurnalis warga di portal tersebut maupun user eksternal. Selain Kompasiana.com, Detik.com juga telah mengembangkan platform jurnalisme warga pasangmata.detik.com sejak 2014 (Bhaskoro, 2014) dan laman minat khusus seperti detikTravel, detikFood, dan detikHealth. Melalui jurnalisme warga dan rubrik-rubrik tersebut, Detik.com pun berupaya mendulang atensi user dan mengganjar user dengan poin atau rewards.

Sementara itu, meniru Kompasiana.com dan Detik.com, Kumparan.com mengundang usernya untuk mengkreasi konten pada alamat web tersebut. Sebagai media online yang pertama kali rilis pada awal 2016, Kumparan.com tidak memiliki media 'ayah maupun ibu'; dalam arti situs tersebut berdiri secara online dan tidak dilahirkan oleh konglomerat media. Kumparan.com bertindak lebih cerdik dari Kompasiana.com. Platform tersebut mewadahi konten buatan pengguna (user generated content/UGC) pada rubrik Opini dan Cerita maupun konten yang disusun oleh redaksi 
profesionalnya pada alamat yang sama yaitu www.kumparan.com. Alih-alih redaksi hanya memilih konten-konten terbaik untuk ditampilkan pada laman muka seperti yang dilakukan Kompasiana.com, pada alamat web yang sama jurnalis profesional Kumparan.com juga mempublikasikan beritanya. Kumparan.com dapat diibaratkan seperti Kompas.com dan Kompasiana.com pada satu halaman yang sama. Cara yang sama juga dilakukan oleh IDNTimes.com yang mengundang anggota komunitas untuk menulis pada platform selain menyediakan konten berita yang disusun profesional oleh jurnalis IDNTimes.com.

Hadirnya portal berita yang menempatkan partisipasi audience pada posisi sentral seperti Detik.com, IDNTimes.com dan Kumparan.com telah melampaui pesimisme yag pernah dilontarkan oleh sejumlah sarjana asing. Menerapkan UGC pada portal berita tidak mudah karena setiap organisasi memiliki kendala struktural dan profesional (Paulussen \& Ugille, 2008). Seringkali kolaborasi jurnalis dan user belum didukung oleh struktur organisasi redaksi berita di mana hirarki maupun pembedaan legacy media dan online masih kuat (Netzer, Tenenboim-Weinblatt, \& Shifman, 2014). Jurnalis kerap terjebak pada rutinitas dan keterbatasan waktu maupun tingginya tekanan. Tak ayal, jurnalis lebih nyaman untuk mengontak sumber-sumber yang sudah dikenal daripada berkolaborasi dengan user. Kekhawatiran banyak jurnalis di Inggris yang meyakini UGC akan menurunkan norma-norma dan nilai-nilai jurnalisme (Singer, 2010) dijawab oleh model kolaborasi ala Kumparan.com yang membuat garis batas tegas antara konten profesional dan konten kreasi warga.

Melalui kacamata bisnis, fitur-fitur partisipasi konvensional hingga UGC tersebut berguna untuk meningkatkan trafik dan memikat pengguna untuk bertahan lebih lama. Manfaat lain dari partisipasi user adalah memperkuat loyalitas terhadap merek, mengurangi ongkos produksi konten, dan membantu mendistribusikan konten 
(Manosevitch \& Tenenboim, 2017). Industri media baru pun melakukan kapitalisasi dari UGC, data pengguna, atau pengguna itu sendiri (e.g. Andrejevic, 2002; Fuchs, 2010). Artikel ini telah menujukkan sejauh mana pelibatan audiens pada sejumlah portal berita di Indonesia. Pelibatan audiens berkaitan dengan model bisnis yang berlaku maupun peluang monetisasi dari partisipasi tersebut (Nixon, 2017; Manosevitch \& Tenenboim, 2017). Kelak, riset perlu dilakukan untuk mendalami kaitan bentuk partisipasi audiens dan potensi kapitalisasi pada masing-masing portal berita.

\section{Referensi}

AMSI (2019). Dari 47 ribu baru 2.700 media online terverifikasi Dewan Pers. AMSI.co.id. Dikunjungi di https://www.amsi.or.id/dari-47-ribu-baru-2700-media-online-terverifikasi-dewan-pers/

Andrejevic, M. (2002). The Work of being watched: Interactive media and the exploitation of self disclosure. Critical Studies in Media Communication, 19(2): 230-248.

Barnes, R. (2014). The "ecology of participation". Digital Journalism, 2(4): 542557.

Bergstorm, A. (2008). The reluctant audience: Online participation in the Swedish journalistic context. Westminster Papers in Communication and Culture, 5(2): 60-80. ISSN 1744-6708 (Print); 1744-6716 (Online).

Bhaskoro, A. T. (2014). Bidik citizen journalism, Detik hadirkan media warga pasangmata. Detik.com, 5 Februari. Diunduh di https://dailysocial.id/post/bidik-citizen-journalism-detik-hadirkanmedia-warga-pasangmata.

Bruns, A. (2009). From prosumer to produser: Understanding user-led content creation. Transforming Audiences. Diunduh di https://eprints.qut.edu.au/27370/.

Ciptadi, S.G. \& Armando, A. (2018). Upaya agensi melawan logika jangka pendek jurnalisme daring: Studi kasus Tirto.id. Jurnal Komunikasi Indonesia, 7(1): 62-72.

Cohen, E.L. (2002). Online Journalism as market-driven journalism. Journal of Broadcasting \& Electronic Media, 46(4):532-548. 
Upperline. (2017, 27 Juli). Disuntik Group Djarum, Kumparan semakin percaya diri melakoni bisnis media daring. Diunduh di http://www.doku.men/post/disuntik-dana-segar-group-djarumkumparan-semakin-percaya-diri-melakoni-bisnis-media-daring.

Dharmasaputra, K. (2011). Jurnalisme online: Asal seru dan saru? ('Online Journalism: Relying on Racy and Raunchy Contents?). Jurnal Dewan Pers ('Press Council Journal') Edisi No. 4 (Januari): 14-24.

Deuze, M. (2003). The web and its journalisms: considering the consequences of different types of news media online. New Media Society, 5:203, DOI: $10.1177 / 1461444803005002004$.

Dewan Pers \& Tim Peneliti PR2Media. (2015). Standar Kompetensi Wartawan: Sumbangannya Bagi Peningkatan Profesionalisme Wartawan. Jurnal Dewan Pers, No. 11, Desember.

Dewi, S. (2018). Najwa Shihab takut tidak bisa gaji pegawai awal bentuk Narasi. IDNTimes.com.

https://www.idntimes.com/news/indonesia/santi-dewi/cerita-najwashihab-takut-tidak-bisa-gaji-pegawai-awal-bentuk-narasi/4 .

Erlangga, M. (2015). CEO DailySocial menjadi salah satu moderator event social media week Jakarta 2015. Dailysocial.id. Dikunjungi di https://dailysocial.id/post/rama-mamuaya-smw-jakarta-2015

Fuchs, C. (2010). Labor in informational capitalism and on the Internet. The Information Society, 26(3): 179-196. DOI: 10.1080/01972241003712215

Gans, H.J. (1980). Deciding What's News : A Study of CBS Evening News, NBC Nightly News, Newsweek, and Time. Illinois: Medill Visions of the American Press \& Northwestern University Press.

Hanitzsch, T. (2005) Journalists in Indonesia: Educated but timid watchdogs. Journalism Studies, 6(4): 493-508.

Hermida, A. \& Thurman, N. (2007). Comments please: How the British news media is struggling with user generated contet. Makalah dipresentasikan pada $8^{\text {th }}$ International Symposium on Online Journalism, Austin, AS, 3031 Maret 2007.

Hill, D. T., Sen, K. (2000). The Internet in Indonesia's New Democracy. The Internet, Democracy and Democratization. London \& New York: Routledge.

Hujanen, J. (2016) Participation and the blurring values of journalism. Journalism Studies, 17(7): 871-880, DOI: 10.1080/1461670X.2016.1171164.

Kammer, A. (2013). Audience participation in the production of online news: 
towards a typology. Nordicom Review, 34:113-126.

Lase, F.J. (2014). McDonaldisasi melalui praktik jurnalisme hibrida di Kompasiana. Jurnal IImu Komunikasi, 11(2): 135-150.

Lewis, S.C. (2012). The tension between professional control and open participation: Journalism and its boundaries. Information, Communication and Society, 15(6): 836-866.

Luik, J. E. (2008). The characteristics of online version of national newspapers in Indonesia and the Philippines. Jurnal IImiah Scriptura, Vol. 2(2):117-123.

Manajemen BeritaSatu Media Holdings (2012). Jurnalisme Positif: Panduan Kerja PAra Jurnalis Berita Satu Media Holding. Diunduh di https://www.beritasatu.com/jurnalisme-positif.

Manan, A. (2013). Potret Pers Jakarta: Laporan Situasi Kebebasan Pers, Bisnis Media \& Kesejahteraan Jurnalis di Jakarta (Portrait of the Press of Jakarta: Situational Report of the Press Freedom, Media Business \& the Prosperity of Journalist in Jakarta). Jakarta: Aliansi Jurnalis Independen.

Manosevitch, I. \& Tenenboim, O. (2017) The multifaceted role of user-generated content in news websites. Digital Journalism, 5(6): 731-752.

Massey, B.L. \& Levy, M.R. (1999). Interactivity, online journalism, and Englishlanguage web newspapers in Asia. Journalism \& Mass Communication Quarterly, 76(1):138-151.

McChesney, R. W. (2003). The Problem of journalism: A Political economic contribution to an explanation of the crisis in contemporary US Journalism. Journalism Studies, 4(3), 299-329.

McManus, J. (1994). Market Driven Journalism. London \& Thousand Oaks, CA: Sage.

MacGregor, P. (2007). Tracking the online audience. Journalism Studies, 8(2): 280-298.

Meehan, E. (1993). Commodity audience, actual audience: The Blindspot Debate. In J.Wasko, V.Mosco \& M.Pendakur (eds), Illuminating the Blindspots: Essays Honouring Dallas W.Smythe, hal. 378-97. Norwood, NJ: Ablex Publishing.

Nugroho, Y., Putri, D.A., \& Laksmi, S. (2012). Mapping the landscape of the media industry in contemporary Indonesia. Jakarta: Creative Common.

Netzer, Y., Tenenboim-Weinblatt, K. \& Shifman, L. (2014). The construction of participation in news websites. Journalism Studies, 15(5). 619-631. 
Nixon, B. (2017). The Business of news in the attention economy: Audience labor and MediaNews Group's efforts to capitalize on news consumption, Journalism. 1 -22.

Paulussen, S. \& Ugille, P. (2008). User generated content in the newsroom: professional and organisational contraints on participatory journalism. Westminster Papers in Communication and Culture, 5(2):24-41.

Schlesinger, P. (1987). Putting "Reality" Together: BBC News, London: Methuen.

Singer, J.B. (2010). Quality control, Journalism Practice, 4(2): 127-142.

Setyowati, D. (2018). Go-Jek dikabarkan tanam modal di Kumparan. Diunduh di https://katadata.co.id/pingitaria/digital/5e9a55d5a012d/go-jekdikabarkan-tanam-modal-di-kumparan.

Souisa, H. Y. (2017). Regulating convergence: Challenges for contemporary media in Indonesia. Asian Journal of Media and Communication, 1(1): 3550 .

Splichal, S. \& Sparks, C. (1994). Journalists for the 21st Century: Tendencies of Professionalization Among First-year Students in 22 Countries. Norwood, NJ: Ablex Pub.

Suciati, N. T. \& Fauziah, N. (2020). Layak berita ke layak jual: nilai berita jurnalisme online Indonesia di era attention economy. Jurnal Riset Komunikasi, 3(1): 51-69.

Sumartias, S. \& Hafizni, Moh. (2017). Convergence trends in the television media industry: a Case study on the implementation of media convergence in Metro TV Jakarta, KnE Social Sciences, 2(4): 83-89.

Sumpter, R. (2000). Daily newspaper editors' audience construction routines: A case study. Critical Studies in Media Communication, 7(3): 335-347.

Thurman, N. (2008). Forums for citizen journalists? Adoption of user generated content initiatives by online news media, 10(1):139-157.

Tunstall, J. (1971). Journalists at Work: Specialist Correspondents, Their News Organizations, News Sources, and Competitor-Colleagues. London: Constable.

Wahl-Jorgensen, W., A., Sambrook, R., Harris, J., Garcia-Blanco, I., Dencik, L., Cushion, S., Carter, C., \& Allan, S. (2016). The Future of Journalism. Journalism Studies, 17:7, 801-807, DOI: 10.1080/1461670X.2016.1199486.

Yusman, R. (2018). Konstruksi media online tentang pemberitaan perizinan 
meikarta di www.beritasatu.com dan www.kompas.comedisi September 2017. Mediakom: Jurnal IImu Komunikasi, 8(1): 15-30.

\section{Profil Penulis}

Gilang Desti Parahita, S.I.P., M.A. Gilang mengajar sejumlah mata kuliah di bidang jurnalisme, komunikasi internasional, komunikasi publik dan komunikasi krisis di Departemen Ilmu Komunikasi FISIPOL UGM. Sejumlah karya mahasiswa peserta kelas-kelas jurnalisme yang ia ampu diunggah di Wargajogja.net. Selain mengajar, Gilang produktif melakukan riset. Riset-risetnya kebanyakan berfokus pada jurnalisme dan media baru dengan isu-isu terkait memori kolektif, kebebasan pers, gender, literasi digital, dan inklusi sosial. Karya-karyanya telah terbit di pelbagai jurnal maupun edited book level nasional dan internasional bereputasi. Karya-karya ilmiah dan rekam jejak pengabdian masyarakatnya dapat diakses di https://acadstaff.ugm.ac.id/gilangparahita. 